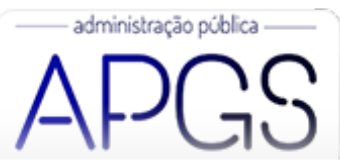

Administração Pública e Gestão Social ISSN: 2175-5787

apgs@ufv.br

Universidade Federal de Viçosa

Brasil

\title{
Efeitos Adversos: um olhar a partir das Políticas Públicas para Povos Indígenas no Brasil
}

\author{
Basques, Messias \\ Efeitos Adversos: um olhar a partir das Políticas Públicas para Povos Indígenas no Brasil \\ Administração Pública e Gestão Social, vol. 13, núm. 4, 2021 \\ Universidade Federal de Viçosa, Brasil \\ Disponible en: https://www.redalyc.org/articulo.oa?id=351568433005
}

\section{(c) $(1) \Theta \theta$}

Esta obra está bajo una Licencia Creative Commons Atribución-NoComercial-SinDerivar 3.0 Internacional. 


\title{
Efeitos Adversos: um olhar a partir das Políticas Públicas para Povos Indígenas no
} Brasil

\author{
Messias Basques \\ Doutor em Antropologia Social pelo Museu Nacional da \\ UFRJ e pesquisador de Pós-Doutorado na FGV EAESP, \\ Brasil \\ messias.basques@gmail.com
}

Adverse effects: a view from Public Policies for Indigenous Peoples in Brazil

Efectos Adversos: una mirada desde las Políticas Públicas para los Pueblos Indígenas en Brasil

Redalyc: https://www.redalyc.org/articulo.oa?

$\mathrm{id}=351568433005$

Recepción: 15 Junio 2020

Aprobación: 14 Marzo 2021

Publicación: 01 Octubre 2021

\section{Resumo:}

Contexto do caso: o caso se insere simultaneamente em dois contextos, apontando-se, assim, elementos de convergência e outros responsáveis pelos insucessos e problemas surgidos do encontro entre os povos indígenas no Brasil e as políticas públicas destinadas a essas populações.

Dilema do caso: o caso recorre a dois referenciais analíticos: uma abordagem histórico-antropológica das relações entre Estado e povos indígenas e a teoria da transformação do "Estado herdado" em "Estado necessário", que vincula o processo de democratização à capacidade estatal de fazer emergir e satisfazer as demandas dos diferentes segmentos da sociedade brasileira. A partir das duas perspectivas, cotejadas em paralelo com dados e depoimentos levantados na imprensa, em documentos oficiais e na literatura especializada, propõe-se aos estudantes que reflitam sobre aspectos problemáticos na construção, implementação e avaliação de políticas indigenistas, com destaque para as questões de saúde.

Fechamento do caso: a narrativa do caso para ensino foi idealizada com o objetivo de oferecer aos estudantes elementos e recursos analíticos que contribuam para a discussão em sala de aula, assim como para a compreensão e identificação de demandas dos povos indígenas; de problemas que impactam sobretudo a saúde, o bem-estar e a qualidade de vida dessas populações; a reflexão acerca de possíveis soluções, baseadas na articulação entre o direito indígena à autodeterminação e as dinâmicas e limites do ciclo de políticas públicas.

Palavras-CHaVe: povos indígenas, políticas públicas, política indigenista.

\section{ABstract:}

Context of the case: The case is simultaneously embedded in two contexts to highlight elements of convergence and others responsible for the failures and problems that arise from the encounter between indigenous peoples in Brazil and the public policies aimed at these populations.

The dilemma of the case: The case draws upon two analytical references: 1) A historical-anthropological approach of the relations between the State and the indigenous peoples in Brazil; 2) The theory of the transformation of the "inherited State" into the "necessary State", which links the democratization process to the State's capacity to bring out and satisfy the demands of the different segments of the Brazilian society. Based on these two perspectives, and in parallel with data and testimonies gathered from the press, official documents, and specialized literature, it is proposed that students reflect on problematic aspects in the construction, implementation, and evaluation of indigenous policies, with emphasis on health issues.

Case closure: The narrative of the teaching case is idealized to offer elements and analytical resources that contribute to the discussion, as well as to the understanding and identification of indigenous peoples' demands; of problems that impact the health, well-being, and life quality of these populations; the reflection about possible solutions, based on the articulation between the indigenous right to self-determination and the dynamics and limits of the cycle of public policies in Brazil.

KEYWORDS: indigenous peoples, public policies, indigenist policy.

\section{ReSUMEN:}


Contexto del caso: el caso se inserta simultáneamente en dos contextos, señalando así elementos de convergencia y otros responsables por los fracasos y problemas derivados del encuentro entre los pueblos indígenas en Brasil y las políticas públicas dirigidas a estas poblaciones.

Dilema del caso: el caso se basa en dos referencias analíticas: un enfoque histórico-antropológico de las relaciones entre el Estado y los pueblos indígenas en Brasil y la teoría de la transformación del "Estado heredado" en el "Estado necesario", que vincula el proceso de democratización a la capacidad del Estado de hacer emerger y satisfacer las demandas de los diferentes segmentos de la sociedad brasileña. A partir de estas dos perspectivas, comparadas en paralelo con datos y testimonios en la prensa, documentos oficiales y literatura especializada, se propone que los estudiantes reflexionen sobre aspectos problemáticos en la construcción, implementación y evaluación de las políticas indígenas, con énfasis en los temas de salud.

Cierre del caso: la narrativa del caso fue idealizada con el objetivo de ofrecer a los estudiantes elementos y recursos analíticos que contribuyan a la discusión, así como a la comprensión e identificación de las demandas de los pueblos indígenas; de los problemas que impactan, sobre todo, en la salud, el bienestar y la calidad de vida de estas poblaciones; la reflexión sobre posibles soluciones, a partir de la articulación entre el derecho indígena a la autodeterminación y la dinámica y los límites del ciclo de las políticas públicas en Brasil.

Palabras ClaVe: pueblos indígenas, políticas públicas, política indigenista.

\section{INTRODUÇÃO: EFEITOS ADVERSOS NAS POLÍTICAS INDIGENISTAS}

Um dos impactos não previstos em programas sociais como o Bolsa Família é a transformação de hábitos alimentares em populações indígenas, um problema que atinge, por exemplo, os povos habitam o Parque Indígena do Xingu (PIX). Para se ter uma ideia da magnitude das mudanças basta lembrar que, na década de 1980, nenhuma pessoa havia sido diagnosticada com hipertensão arterial ou diabetes mellitus em um amplo inquérito conduzido no local. Quase quarenta anos depois, o cenário é outro. Uma pesquisa da Universidade Federal de São Paulo realizada entre os Kisêdjê demonstrou que $84 \%$ das pessoas apresentavam taxas excessivas ou anormais de colesterol e triglicerídeos, enquanto $57 \%$ dos homens e $36 \%$ das mulheres sofriam com excesso de peso ${ }^{[\mathrm{i}]}$. A combinação do consumo de alimentos industrializados com o processo recente de sedentarização da vida também é responsável pela elevada incidência de obesidade, diabetes e doenças coronarianas entre os Xavante, em Mato Grosso.

Para Douglas Rodrigues, médico e coordenador do Projeto Xingu, a introdução repentina de programas sociais nessas populações pode ter efeitos devastadores ${ }^{[i i]}$. No caso específico do Programa Bolsa Família (PBF), a necessidade de deslocamento para o recebimento do benefício tem provocado a alteração do cotidiano das comunidades e, em muitos casos, a migração de famílias inteiras para as cidades próximas. $\mathrm{Na}$ opinião de Artur Mendes, ex-presidente da Fundação Nacional do Índio, o vínculo obrigatório com a cidade é responsável pelo esvaziamento das aldeias e pela mudança de hábitos, atingindo inclusive os mais velhos, pois a situação se repete entre os beneficiados pela aposentadoria rural. ${ }^{[i i i]}$

O PBF foi instituído com a Medida Provisória n. 132, de 20 de outubro 2003. No ano seguinte, a medida foi convertida em lei (n. 10.386) e a gestão foi atribuída ao Ministério do Desenvolvimento Social e Combate à Fome. Trata-se de um programa idealizado sob a lógica intersetorial, cuja execução depende da articulação de uma ampla rede de entes federativos. $\mathrm{O}$ instrumento que permite a unificação das ações é o Cadastro Único, que reúne as informações relativas aos usuários de programas sociais do governo federal. O PBF baseiase em um modelo de transferência de renda com condicionalidades nas áreas de saúde, educação e assistência social, como componentes de uma estratégia mais ampla para a interrupção do ciclo intergeracional da pobreza. Para tanto, as famílias contempladas devem matricular os filhos de 6 a 17 anos em escolas, manter em dia a vacinação dos mesmos e realizar o pré-natal, com acompanhamento nutricional e de saúde. Atualmente, cerca de $60 \%$ das famílias indígenas recebem o Bolsa Família em todo o país. ${ }^{[i v]}$

Os pesquisadores responsáveis pelo relatório de avaliação do PBF entre povos indígenas, publicado em 2016, afirmam que o programa tem contribuído para a sustentabilidade alimentar, permitindo a compra de alimentos, utensílios e ferramentas utilizados em atividades agrícolas e de pesca. Porém, advertem que é 
preciso repensar a relação do PBF com as condicionalidades de saúde, pois identifica-se a precariedade do sistema de acompanhamento, a falta de capacitação dos profissionais e a baixa integração das instituições do poder público. Por esses motivos, sugerem a construção de um "Subprograma Bolsa Família Indígena”, como ocorre no Sistema Único de Saúde, e que o novo subsistema passe a integrar o conjunto das ações sociais do Ministério.[v]

A preocupação de lideranças indígenas com o atual estado de coisas é recorrente em todo o país, pois o foco do PBF é o combate à pobreza, mas eles e elas não se veem como "pobres" ou "miseráveis", a não ser, justamente, nos casos em que estão destituídos de seus territórios e modos de vida, como ocorre com comunidades guarani e kaiowá em Mato Grosso do Sul. No Amapá, os Wajãpi estão vivendo um processo crescente de consumo de alimentos industrializados, que é acompanhado pelo desinteresse dos jovens pelo trabalho agrícola tradicional. Neste contexto, não são apenas os corpos que mudam, mas principalmente o modo de existência dessas pessoas.[vi] O agente de saúde Marcelo Kamayurá, da aldeia Morená no PIX, defende que não se trata de encerrar os programas sociais, mas sim de adaptá-los ${ }^{[\text {vii] }}$. Por outro lado, na opinião da artista Watatakalu Yawalapiti, coordenadora da área de mulheres da Associação Terra Indígena Xingu, algumas mudanças relacionadas aos programas sociais, como o PBF e o salário-maternidade, são positivas e bem vindas, o que se poderia comprovar pela maior autonomia das mulheres indígenas na criação dos filhos, sem a obrigatoriedade da presença masculina ou da aceitação de "casamentos arranjados" [viii]. Em suma, pode-se dizer que faltam aos programas sociais e às políticas públicas uma maior atenção às demandas e à realidade de cada povo.

Os problemas mencionados são agravados pela ineficiência da política pública de saúde, apesar do aumento dos investimentos nas últimas décadas. Paulo Supretaprã, ex-cacique da aldeia xavante de Etênhiritipá, oferece uma síntese desse cenário ao dizer que a política de saúde falha por não oferecer, de modo contínuo, os serviços previstos na atenção básica e o tratamento de doentes crônicos. Na opinião de Supretaprã, faltam insulina e medicamentos anti-hipertensivos nos postos de saúde; a visitação das equipes multiprofissionais às aldeias é dificultada pela falta de combustível e de viaturas, com consequências para o acompanhamento de pacientes e cumprimento do calendário vacinal; a infraestrutura dos postos de saúde é precária, não havendo, por exemplo, a possibilidade de refrigeração de soro antiofídico. ${ }^{[i x]}$

O número de partos cirúrgicos tem aumentado nos últimos anos e em alguns estados, como no Paraná, está acima do indicado pela Organização Mundial de Saúde, que é $15 \%{ }^{[\mathrm{x}]}$. A situação contraria não somente os costumes indígenas, mas também o crescente movimento de mulheres que buscam as casas de parto humanizado nas grandes cidades brasileiras, como revela o caso de Lourdes Firmino, indígena do povo Ticuna no Estado de Amazonas, que se preparou para o parto natural durante o pré-natal, mas teve a sua vontade contrariada pela decisão dos médicos de realizar o procedimento cirúrgico, interrompendo a evolução do trabalho de parto. Lourdes, que também atua como parteira, explica que desde que não haja nenhuma complicação ou risco, o parto tem que ser feito no "tempo da mulher" e de acordo com a sua cultura ${ }^{[\mathrm{xi}]}$.

A preocupação com o cenário reportado pela imprensa, por líderes indígenas e especialistas exige uma reflexão sobre a responsabilidade do Estado e os marcos legais que regulam a sua atuação. A Constituição Federal de 1988, no "Capítulo 8: Dos Índios”, assegura o direito à autodeterminação, que consiste na garantia de que possam viver segundo os seus costumes, crenças, tradições e formas de organização social e política, entendimento que também se aplica às políticas públicas, cujo ciclo deve basear-se tanto em uma ação intersetorial quanto na compreensão da diversidade sociocultural e linguística do público-alvo. No que se refere às políticas de saúde, não se trata apenas de prevenir e tratar doenças, mas de garantir a continuidade dos modos de vida. Especialmente agora, em plena pandemia de COVID-19, quando a vulnerabilidade sociodemográfica e infraestrutural dos povos indígenas os expõem ao risco iminente de genocídio, conforme alertam especialistas e lideranças tradicionais ${ }^{[x i i]}$. Por esses motivos, a reflexão sobre as políticas indigenistas 
exige a consideração dos âmbitos territoriais e ecológicos implicados nas definições de bem viver de cada um dos mais de 250 povos presentes no Brasil.

\section{OS INDÍGENAS, o ESTAdo E A POLÍ́TICA: ANTECEDENTES E CONTEXTO}

Foi apenas no Brasil Republicano que surgiu o primeiro serviço de Estado voltado exclusivamente aos povos indígenas. Os episódios de violência e os conflitos fundiários motivaram a criação, em 1910, do Serviço Nacional de Proteção aos Índios e Localização de Trabalhadores Nacionais. Anos mais tarde, o nome foi alterado para Serviço de Proteção aos Índios (SPI). O SPI tinha como patrono o Marechal Cândido Rondon, que pretendia "civilizar" os indígenas a partir de uma visão positivista, integracionista e "tolerante”, movido pelo lema: "morrer se preciso for, matar nunca". O SPI promoveu a criação de reservas, o processo de sedentarização e aldeamento, incentivou a criação de "guardas indígenas", o ensino de português e o ensino técnico, ao mesmo tempo em que disponibilizava extensas áreas de ocupação tradicional para a produção agropastoril. Os resultados dessa "Marcha para o Oeste” repercutem ainda hoje na grave situação humanitária em que se encontram os Guarani e os Kaiowá, em Mato Grosso do Sul.

No final da década de 1960, o SPI foi dissolvido em meio a denúncias de corrupção, violação de direitos e mortes de indígenas. O Promotor Jader de Figueiredo Correia realizou uma extensa investigação, que deu origem ao relatório que leva o seu nome. Em 1967, o SPI foi extinto e, no seu lugar, foi criada a Fundação Nacional do Índio (Funai). Durante o regime militar, as populações indígenas apareceram como "obstáculos" ao desenvolvimento e à soberania nacional, sofrendo as consequências de uma série de epidemias difundidas com a expansão da fronteira agropastoril e de grandes empreendimentos.

Lideranças indígenas organizaram assembleias e coletivos que, pouco a pouco, deram origem a movimentos de alcance regional e nacional. Participaram ativamente do processo constituinte e, com o apoio de ativistas e aliados, conseguiram modificar a política indigenista e o texto final da Constituição Federal de 1988. No lugar da integração e da assimilação, entrava em cena o direito à autodeterminação. Ao contrário das constituições anteriores, os direitos indígenas apareceram em um capítulo específico, em dois artigos.

Em paralelo às garantias constitucionais, deve-se destacar a Convenção 169 da Organização Internacional do Trabalho, de junho de 1989, ratificada pelo Brasil em julho de 2002. Desde a redemocratização, a política indigenista se baseia no fim da tutela e no reconhecimento do protagonismo indígena na gestão dos territórios, assim como na formulação, implementação e avaliação de políticas públicas. Desse modo, foram criadas a Secretaria Especial de Saúde indígena e projetos educacionais específicos, que preveem a formulação de currículos estruturados nos territórios, saberes e idiomas nativos.

Segundo os dados do Censo de 2010 e do Instituto Socioambiental (2017), estima-se a população indígena entre 700 e 900 mil pessoas, distribuídas em 252 povos, falantes de mais de 160 línguas. No total, são 704 as terras indígenas, sendo 113 as que se encontram em processo de identificação, 39 as identificadas, 72 as declaradas, e 480 as reservadas ou homologadas, cujos processos jurídico-administrativos foram devidamente concluídos. Essas terras ocupam 13,8\% da extensão territorial do país, sendo que 98,42\% delas estão na Amazônia Legal, em condição de sobreposição com áreas de conservação e (ou) de preservação ambiental. ${ }^{\text {[xii] }}$

As críticas em torno da extensão dessas áreas se baseiam no argumento de que "é muita terra para pouco índio". Porém, desde o Brasil Colônia, a tese do "indigenato" esteve presente em praticamente todas as constituições e leis relativas à propriedade de terras. Trata-se do reconhecimento de que as terras habitadas pelos indígenas são protegidas por um direito congênito e, portanto, anterior ao próprio Estado brasileiro. 


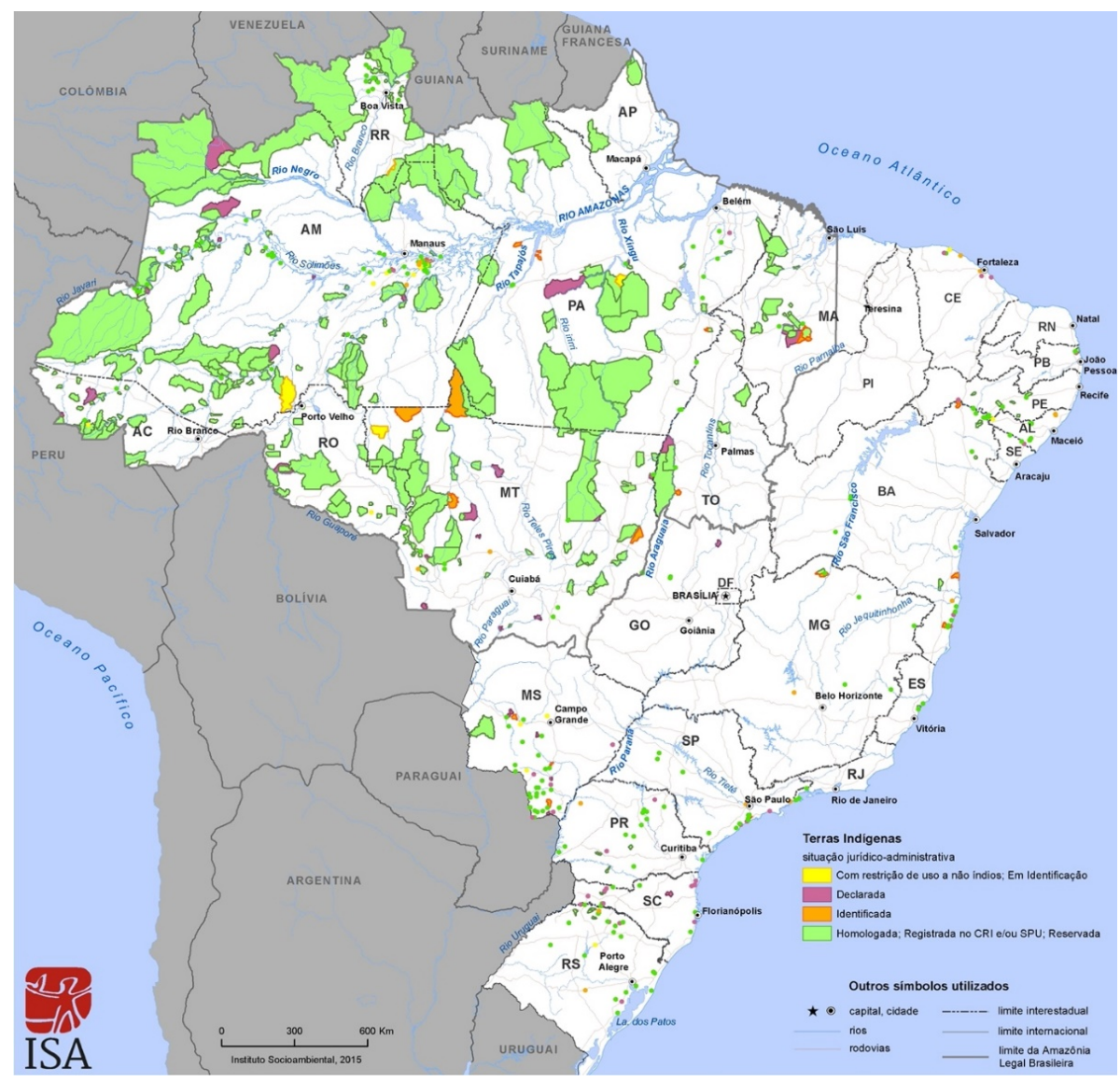

FIGURA 1

Localização e extensão das terras indígenas Fonte Instituto Socioambiental

Com a promulgação da Constituição Federal de 1988 foi estabelecido o prazo de cinco anos para a conclusão das demarcações de terras indígenas. Nos anos seguintes, foi criado o Projeto Integrado de Proteção às Populações e Terras Indígenas da Amazônia Legal (PPTAL), que promoveu a identificação e a demarcação de dezenas de territórios, embora o foco na Amazônia tenha provocado uma concentração dos conflitos fundiários em outras regiões do país, como nos estados de Mato Grosso do Sul, Rio Grande do Sul e no nordeste brasileiro.

O PPTAL antecede a atual Política Nacional de Gestão Territorial e Ambiental de Terras Indígenas (PNGATI), que foi construída com a participação direta da sociedade civil. O marco legal é o Decreto n. 7.747, de 5 de julho de 2012. De acordo com o Art. 1º o objetivo principal da PNGATI é: "Garantir e promover a proteção, a recuperação, a conservação e o uso sustentável dos recursos naturais das terras e territórios indígenas, assegurando ... as condições plenas de reprodução física e cultural das atuais e futuras gerações”. Vê-se, assim, que a intersetorialidade é um fator determinante quando se trata de pensar políticas destinadas aos povos indígenas. Não é possível conceber uma política nacional, como a PNGATI, sem considerar a sua relação direta com os temas da saúde, assistência social e educação.

No que se refere à saúde, a garantia da atenção diferenciada tem um antecedente primordial: a Conferência Alma-Ata das Nações Unidas, de 1978, no Cazaquistão. Naquela oportunidade, discutiu-se a necessidade de promover a saúde de todos os povos do mundo a partir da ideia de completo bem-estar físico, mental e social, e não simplesmente da ausência de doença ou de enfermidades. Foi esta a compreensão que orientou a criação do Sistema Único de Saúde (SUS), em setembro de 1988. A construção do Subsistema de Atenção à Saúde Indígena (SASI) ocorreu dois anos depois, como resultado de reuniões com a participação de lideranças e representantes de todo o país. No lugar da fragmentação das políticas indigenistas anteriores e dos vieses da 
assimilação e da integração, surgiu uma concepção mais democrática e inclusiva, o que possibilitou a criação de mecanismos de controle social, bem como a formação e a contratação de profissionais indígenas.

A regulamentação da Política Nacional de Atenção à Saúde dos Povos Indígenas (PNASPI) só se concretizou no ano de 2000, com um investimento na descentralização das ações e dos recursos. O modelo organizacional do subsistema previa a criação de 34 Distritos Sanitários Especiais Indígenas (DSEIs), cada qual com os seus respectivos polos-base, postos de saúde e casas de acolhimento. A $4^{a}$ Conferência Nacional, em 2006, resultou na formação de grupos de trabalho entre os representantes indígenas e do poder público, o que levou à criação da Secretaria Especial de Saúde Indígena (SESAI), em 2010.

Em termos de orçamento e estrutura houve uma evolução significativa nas últimas décadas, embora as comunidades e lideranças, respaldadas por especialistas e pesquisadores, denunciem que não houve melhora proporcional dos indicadores de saúde. Gasta-se muito dinheiro com diárias, combustível, contratos de transporte aéreo, locação de imóveis e hotéis para eventos, mas faltam remédios e insumos nos postos de saúde das aldeias. O Inquérito Nacional de Saúde dos Povos Indígenas, o único instrumento oficial com abrangência nacional, tem demonstrado a persistência de anemia e desnutrição entre crianças menores de 5 anos, e a presença da obesidade, do diabetes e da hipertensão entre adultos, além de doenças crônicas e do aumento de infecções sexualmente transmissíveis. Como dito acima, até mesmo as políticas de segurança alimentar e distribuição de renda, como o Bolsa Família, têm contribuído para a piora dos indicadores de saúde, uma vez que promovem uma ruptura drástica de hábitos alimentares e de consumo.

Um dos problemas mais relevantes no monitoramento das políticas de saúde indígena é a "invisibilidade estatística”, que decorre da ineficiência do registro e da inserção de dados no sistema de informações da SESAI, o SIASI. Contudo, o aprimoramento do sistema não eliminaria os problemas de confiabilidade e consistência nos bancos de dados, uma vez que a maioria dos DSEIs e polos-base vive uma intensa rotatividade em seus quadros de funcionários, o que prejudica a inclusão e a atualização de informações a respeito da incidência de doenças, dos atendimentos, do uso de medicação e da cobertura das campanhas de vacinação.

Daí a importância de ampliar a formação de profissionais indígenas que, na quase totalidade dos casos, regressam às suas comunidades após a conclusão de cursos técnicos e universitários, em busca de oportunidades de trabalho nas escolas e postos de saúde das aldeias. Preocupada com o tema, a Deputada Federal Joênia Wapichana apresentou um Projeto de Lei (n. 3514/2019) que pretende regulamentar as profissões de agente indígena de saúde e saneamento.

Uma das experiências mais bem-sucedidas nesse sentido é a da Escola Paulista de Medicina, a partir de sua atuação no Parque Indígena do Xingu, iniciada no ano de 1965. O projeto levou campanhas de vacinação, atendimento médico e acompanhamento aos povos indígenas da região, trazendo ao Hospital São Paulo os pacientes acometidos por doenças graves para a realização das cirurgias e de tratamentos de alta complexidade. Desde o início do Projeto Xingu, os profissionais de saúde promoveram parcerias e diálogos com pajés e lideranças indígenas. Com a retirada gradual dos funcionários da Funai nos anos seguintes, o projeto passou a investir na formação e no treinamento de agentes indígenas de saúde e na criação do Ambulatório do Índio, em São Paulo. Em julho de 2001, ocorreu a formatura da primeira turma de Auxiliares de Enfermagem Indígena, com 16 pessoas. A atuação da universidade foi decisiva para o aumento populacional registrado nos últimos anos no PIX, assim como para o controle de doenças como a malária e o sarampo. Ao longo de quatro décadas de Projeto Xingu, foram criadas bolsas que financiam as atividades de novos pesquisadores e médicos, garantindo a continuidade do projeto e do diálogo intercultural. 
Tabela 1 - A Proteção "fraternal" e o "poder tutelar"

\begin{tabular}{|l|l|}
\hline $\begin{array}{l}\text { 1899: Brasil } \\
\text { República }\end{array}$ & "Forjar" um povo, conservar a integridade do território nacional \\
\hline $\begin{array}{l}\text { 1910: } 1^{a} \text { Política } \\
\text { Indigenista oficial }\end{array}$ & $\begin{array}{l}\text { Criação do Serviço de Proteção aos Índios e Localização de Trabalhadores Nacionais, } \\
\text { renomeado para Serviço de Proteção aos Índios (SPI), em 1918. Missão: solucionar os } \\
\text { conflitos nas áreas de expansão da "fronteira agropastoril" e gerir as populações } \\
\text { indígenas, disponibilizando terras para ocupação de produtores rurais e migrantes }\end{array}$ \\
\hline Estratégias do SPI & $\begin{array}{l}\text { Combatia-se o "nomadismo" com a criação de reservas, postos e colônias, sob os } \\
\text { lemas da "pacificação" e da civilização dessas populações. Proibição do ensino e do } \\
\text { uso de idiomas indigenas. Ensino do português e ensino técnico como instrumentos } \\
\text { para a conversão dos nativos em trabalhadores, "integrados" à sociedade nacional }\end{array}$ \\
\hline $\begin{array}{l}\text { Código Civil de } \\
1916\end{array}$ & $\begin{array}{l}\text { Indígenas definidos como "relativamente incapazes", como os maiores de 16 e } \\
\text { menores de 21 e as mulheres casadas. "Indígena" como categoria transitória: ideais de } \\
\text { integração e assimilação dessas populações à sociedade nacional }\end{array}$ \\
\hline
\end{tabular}

Tabela 2 -A "superação" da tutela

\begin{tabular}{|c|c|}
\hline 1948 & eclaração Universal dos Direitos do Homem e a crítica ao racismo colonialista \\
\hline 1957 & $\begin{array}{l}\text { Convenção } 107 \text { da Organização Internacional do Trabalho sobre a "Proteção de Populações } \\
\text { Indígenas e Tribais" }\end{array}$ \\
\hline 1961 & $\begin{array}{l}\text { Criação dos "Parques Indígenas", como o Parque Indígena do Xingu, que se torna a "vitrine do } \\
\text { indigenismo brasileiro" }\end{array}$ \\
\hline 1967 & $\begin{array}{l}\text { Extinção do SPI: a CPI de Jader Figueiredo documenta inúmeros casos de corrupção, violência, tortura } \\
\text { e todo o tipo de arbitrariedades cometidas contra as populaçoes indígenas no Brasil. No mesmo ano, } \\
\text { cria-se a Funai, com o objetivo de exercer o "monopólio tutelar" }\end{array}$ \\
\hline 1973 & $\begin{array}{l}\text { "Estatuto do Índio": reedição da ideia de tutela e avanço das políticas desenvolvimentistas do regime } \\
\text { militar na Amazônia }\end{array}$ \\
\hline 1977 & Proposta de "emancipação dos índios" \\
\hline 1988 & $\begin{array}{l}\text { A nova Constituição Federal é promulgada com um capítulo exclusivo para os indígenas. Cap. } 8 \text { - } \\
\text { "Dos índios": Art. } 23 \text {. São reconhecidos aos índios sua organização social, costumes, línguas, crenças } \\
\text { e tradições, e os direitos originários sobre as terras que tradicionalmente ocupam, competindo à União } \\
\text { demarcá-las, proteger e fazer respeitar todos os seus bens. Art. 232. Os índios, suas comunidades e } \\
\text { organizações são partes legítimas para ingressar em juízo em defesa de seus direitos e interesses, } \\
\text { intervindo o Ministério Público em todos os atos do processo }\end{array}$ \\
\hline 1989 & $\begin{array}{l}\text { Convenção } 169 \text { da Organização Internacional do Trabalho, ratificada pelo Brasil em 2004. Estabelece } \\
\text { o princípio da autodeterminação e a obrigatoriedade de consulta prévia e do consentimento livre, } \\
\text { esclarecido e informado }\end{array}$ \\
\hline 1999 & "Lei Arouca", n. 9836: criação do subsistema de saúde específica e diferenciada \\
\hline 2002 & Políti \\
\hline 2002 & Política Nacional de \\
\hline 2003 & ligo Civil extingue a figura da "capacidade relativa" e põe fim ao paradigma da tutela \\
\hline
\end{tabular}

\section{Os DESAFios E AS ALTERNATIVAS: DUAS PROPOSTAS ElaboradAS EM SALA DE AULA}

Os temas da saúde indígena e dos efeitos adversos das políticas públicas indigenistas foram debatidos com estudantes de Administração Pública, durante um curso de imersão. Inicialmente, apresentou-se um panorama do caso e do contexto, baseado em depoimentos de atores diretamente envolvidos com a questão, além de dados históricos, demográficos e epidemiológicos disponíveis na literatura especializada, nas fontes oficiais e na imprensa. Em seguida, os estudantes foram incentivados a trabalhar em grupos, a fim de identificar problemas e de elaborar propostas de aprimoramento da legislação e das políticas indigenistas. Seguem abaixo os resumos de duas das dez propostas elaboradas durante o curso, a fim de ilustrar algumas das possíveis soluções para os problemas evidenciados no caso de ensino. 


\subsection{Saúde da Mulher Indígena no Brasil: Maternidade e uma Proposta Legislativa de Casas de Parto. Autores: Andressa Garcia, Dora Cavalcanti Ehrlich, Gabriel Salles, Guilherme Calixto, Laura Portela, Paola de Angelis.}

Diagnóstico: o Brasil é o segundo país com maior taxa de partos cirúrgicos no mundo, situação que contraria as recomendações da Organização Mundial de Saúde. Em termos percentuais, entre as mulheres indígenas quase a totalidade dos partos são normais/vaginais ou naturais (sem intervenção médica). Porém, o número de partos cirúrgicos tem aumentado rapidamente, sobretudo quando o parto ocorre em ambiente hospitalar. Uma alternativa seria a criação de casas de parto especializadas no atendimento de gestantes indígenas que se encontrem, por qualquer razão, no ambiente urbano.

Objetivo: reduzir os partos cirúrgicos, uma vez que, quando desnecessários, podem ser prejudiciais à saúde da mulher e dos recém-nascidos, além de a prática contrariar as culturas e os costumes indígenas; capacitar os profissionais das casas de parto para que avaliem o eventual risco em partos normais/vaginais ou naturais; preservar a placenta (nos casos de povos que tenham costumes e tradições relacionados ao órgão maternofetal); contratar parteiras indígenas; oferecer acolhimento em locais equipados com redes e outros utensílios comuns às habitações indígenas.

Proposta:

a) Alteração do Artigo $19 \$ 2^{\circ}$ da Lei n. 9.836 de 1999, também conhecida como Lei Arouca, que instituiu o Subsistema de Atenção à Saúde Indígena;

Redação original: "O SUS servirá de retaguarda e referência ao Subsistema de Atenção à Saúde Indígena, devendo, para isso, ocorrer adaptações na estrutura e organização do SUS nas regiões onde residem as populações indígenas, para propiciar essa integração e o atendimento necessário em todos os níveis, sem discriminações".

Inclusão: "Assim como existem Casas de Parto reconhecidas pelo SUS, as mesmas podem e devem ser adaptadas às realidades e necessidades de saúde de mulheres e gestantes indígenas. As Casas de Parto devem atender às especificidades culturais dessas populações, nas regiões em que se encontram. Além disso, devem respeitar à cultura alimentar de cada comunidade".

b) Alteração do Decreto n. 3.156, de 27 de agosto de 1999, que dispõe sobre as condições para a prestação de assistência à saúde dos povos indígenas, no âmbito do Sistema Único de Saúde:

Inclusão: estabelecimento do processo de consulta às comunidades indígenas a respeito das casas de parto e dos costumes e procedimentos que devem ser seguidos; contratação, quando possível, de profissionais indígenas das comunidades atendidas, que serão responsáveis pelo acompanhamento de saúde das mulheres e das gestantes, assim como pela orientação sobre a prevenção de infecções sexualmente transmissíveis; adaptação do espaço físico das casas de parto para acolhimento de mulheres indígenas.

\subsection{Guia Alimentar para Povos Indígenas: uma nova perspectiva. Autores: Alessandra Pignalosa, Bruna Ferreira, Lorena Perez, Paula Souza.}

Diagnóstico: o Programa Bolsa Família (PBF) adquiriu grande importância na provisão de alimentos, o que se deve a diversos fatores, como a diminuição de atividades produtivas tradicionais, a degradação ambiental e as ameaças externas aos territórios indígenas. A alteração dos hábitos alimentares tem efeitos negativos para a saúde e também provoca a perda de práticas e costumes tradicionais. As definições de segurança alimentar e nutricional estabelecidas no Brasil seguem a recomendação da Organização Mundial da Saúde, que sugere a proposição de diretrizes nacionais sobre alimentação e nutrição, bem como a sua constante atualização, em virtude das mudanças sociais. Nesse sentido, em 2006, o governo federal lançou o primeiro guia alimentar para a população brasileira, mas não incluiu uma seção específica para povos indígenas. 
Objetivos: elaborar e distribuir um Guia Alimentar para Povos Indígenas, mediante consultas a representantes, lideranças e pesquisadores indígenas. Efetivar os direitos garantidos pela Lei Orgânica de Segurança Alimentar e Nutricional (Lei n. 11.346 de 2006), em conformidade com a Constituição Federal de 1988, e proporcionar uma alimentação de qualidade e com valor nutricional.

Proposta: o guia será utilizado como documento base para apontar diretrizes e recomendações de alimentos específicos para cada povo, considerando-se o tipo de bioma e região em que vivem. Por intermédio do PBF, será incentivado o cultivo de alimentos tradicionais e (ou) parcerias com pequenos produtores locais, próximos às aldeias (nos casos de aldeias, reservas e terras indígenas sem áreas suficientes para o cultivo). $\mathrm{O}$ Guia servirá de diretriz para a alimentação escolar indígena, assim como para a alimentação oferecida nas instituições de acolhimento da política indigenista. Serão elaboradas recomendações de segurança alimentar, com respeito às singularidades locais, culturais e sociais de cada povo. O Guia poderá ser traduzido para os idiomas indígenas, a fim de colaborar para a perpetuação da cultura e dos processos escolares de ensino e aprendizagem, além de servir como instrumento de documentação complementar dos idiomas que se encontram em risco de extinção.

\section{Questões PARA a REFleXão}

O Brasil é um país multiétnico. Embora o adjetivo não apareça no texto da Constituição Federal de 1988, faz-se referência à obrigatoriedade de que o ensino da História do Brasil deve contemplar "as contribuições das diferentes culturas e etnias para a formação do povo brasileiro” (Art. $242 \$ 1^{\circ}$ ). Nesse sentido, cabe ao Estado proteger "as manifestações das culturas populares, indígenas e afro-brasileiras, e de outros grupos participantes do processo civilizatório nacional” (Art. $215 \$ 1^{\circ}$ ). Porém, as garantias constitucionais contrastam com a ausência dos povos indígenas, bem como de suas culturas, idiomas, costumes e conhecimentos, na formação escolar e universitária da maioria das instituições de ensino brasileiras, sejam elas públicas ou privadas.

Pela leitura do caso, os estudantes poderão compreender que os desafios das políticas indigenistas são agravados pelo desconhecimento a respeito dos povos indígenas e de sua contribuição à formação do Brasil contemporâneo. A iniciativa de oferecer aos estudantes de Administração Pública uma aproximação à questão indígena cumpre uma função importante, que consiste em incentivar o desenvolvimento de uma "sensibilidade antropológica" acerca da diversidade sociocultural e linguística que caracteriza o país (Souza Lima \& Macedo Castro, 2015; Souza Lima, 2002).

Uma vez que nos tornamos sensíveis à realidade indígena e às suas especificidades, cabe aos estudantes e futuros profissionais refletir sobre algumas questões fundamentais: Como podemos contribuir para o aprimoramento da legislação e da política indigenista? Como os profissionais da área podem atuar no terceiro setor, nas empresas privadas, em organizações não governamentais, na gestão de políticas públicas ou no serviço público de modo a respeitar e promover a autodeterminação dos povos indígenas?

\section{Notas de Ensino}

\subsection{Objetivos de aprendizagem}

O objetivo do caso é ilustrar alguns dos desafios das políticas indigenistas no Brasil, de maneira exploratóriodescritiva, baseando-se em dados oficiais, na cobertura jornalística e nas perspectivas de atores diretamente envolvidos com a questão: lideranças indígenas, pesquisadores e gestores públicos. Aplica-se para a discussão sobre políticas públicas em cursos de Administração Pública, Ciências Sociais e afins. 


\subsection{Apontamentos teóricos}

O Brasil é um país multiétnico, ainda que tenhamos nos acostumado a supor a existência de um único povo brasileiro. $\mathrm{Na}$ formação escolar e universitária, os currículos geralmente não abordam a diversidade sociocultural e linguística presente no país, o que colabora para a ausência das temáticas indígenas e afrobrasileiras na trajetória de estudantes e na sua futura atuação profissional. Não por acaso, produziu-se um "isolamento dos índios no pensamento brasileiro" (Monteiro, 2001, p. 4), que se torna evidente quando consideramos a literatura dedicada à história indígena e que se resume, ao menos até a década de 1980, na reiterada "crônica de sua extinção" (Monteiro, 2001, p. 6).

O estudo das versões oficiais da história do Brasil revela um "processo de construção da identidade nacional mediante mecanismos políticos e discursivos de sistemático apagamento” (Pompa, 2014, p. 72) da contribuição indígena. Oliveira (2016, p. 11) sugere que as nossas "autorrepresentações" e "mitos de origem" permitem compreender a "reelaboração radical do passado, com a sistemática exclusão e ressemantização dos fatos históricos". Na interpretação do autor, trata-se de "uma modalidade peculiar de esquecimento" e que tem como efeito a produção de "um regime de invisibilidade" (Oliveira, 2016, p. 110).

Por esses motivos, prevalece no senso comum a ideia de que o país é o resultado da equação: um povo = um território $=$ um idioma $=$ uma cultura $=$ uma identidade. A incompreensão da sutil diferença entre os enunciados "índios no Brasil" e "índios do Brasil” está diretamente relacionada a essa equação equivocada, sobre a qual se fundamenta o imaginário da "identidade nacional". Ainda que eles estejam entre nós, a sua presença é anterior à invenção do país. Os seus modos de vida não se resumem à relação com o Estado nem com a sociedade nacional. Confunde-se o princípio universalista de que todos são iguais perante às leis, sem distinção de qualquer natureza, com a necessidade de uma ação estatal genérica e uniforme, a despeito das diferentes necessidades dos grupos que compóem o "povo" brasileiro.

Desde o período colonial, investiu-se na conversão dos povos nativos como forma de integrá-los a uma comunidade abrangente. $\mathrm{Na}$ atuação dos missionários, a conversão religiosa servia de instrumento para a "redução" (no sentido original da palavra, para a "reorientação") das almas ao cristianismo e dos corpos à ideia ocidental de trabalho. A partir do início do século XX, com a criação do Serviço de Proteção aos Índios (SPI), tentou-se impor uma "reorientação republicana", laica e positivista, baseada nas ideias de que a condição indígena seria transitória e de que ocorreria, gradativamente, a integração à sociedade brasileira.

Durante o governo do general Ernesto Geisel (1974-1978), o então ministro do Interior, Rangel Reis, defendeu uma mudança ainda mais radical na atuação do Estado. A proposta previa a alteração do Estatuto do Índio, de 1973, revendo os seus princípios fundamentais, a fim de promover a "emancipação indígena”. No Artigo $1^{\circ}$ do Estatuto definia-se que a lei passava a regular "a situação jurídica dos índios ou silvícolas e das comunidades indígenas, com o propósito de preservar a sua cultura e integrá-los, progressiva e harmoniosamente, à comunhão nacional". O Artigo $7^{\circ}$ determinava a sujeição ao regime tutelar e instituía a assistência do Estado, condições que poderiam ser revogadas mediante a apresentação de requerimento a um juiz competente para a liberação do regime e o reconhecimento da "plenitude de capacidade civil", desde que preenchidos os seguintes requisitos: idade mínima de 21 anos, conhecimento da língua portuguesa, "habilitação para o exercício de atividade útil, na comunhão nacional" e "razoável compreensão dos usos e costumes" da sociedade brasileira.

O regime tutelar foi incluído no Código Civil no ano de 1916. Ainda que o dispositivo tenha sido concebido como uma forma de "proteção" jurídica, serviu de instrumento para a imposição de uma série de medidas administrativas e de políticas públicas opostas aos interesses e necessidades de seu público-alvo. Do Serviço de Proteção aos Índios à Funai, criada em 1967, a legitimidade jurídica da representação dessas comunidades ficou a cargo do Estado, reduzindo os seus integrantes à condição de menoridade.

O projeto de "emancipação" representou mais um capítulo da história da "redução" político-religiosa, sob a justificativa de transformá-los em trabalhadores e de assegurar a realização de projetos de desenvolvimento 
econômico na Amazônia. Houve forte oposição na sociedade civil e de lideranças indígenas, uma vez que o projeto promovia o desaparecimento da "etnicidade" e dos modos de vida tradicionais. Na 30a Reunião Anual da Sociedade Brasileira para o Progresso da Ciência, realizada no mês de julho de 1978, em São Paulo, aprovou-se uma moção de repúdio ao projeto de Rangel Reis, com base no seguinte entendimento:

A chamada "emancipação do índio" configura mais uma ameaça para essas populações. ... Sem a demarcação das terras indígenas é impossível respeitar a diversidade cultural e permitir um processo de interação em bases mais justas entre as sociedades indígenas e a sociedade nacional, que é fundamento de toda emancipação verdadeira. (como citado em Bicalho, 2019, p. 146).

As manifestações contrárias ao decreto fizeram o regime recuar, revelando uma crescente articulação indígena em todo o processo de redemocratização. As assembleias, conselhos e associações surgidas naquele momento deram origem a movimentos de alcance regional e nacional. Os indígenas também participaram ativamente do processo constituinte e, com o apoio de ativistas e aliados, conseguiram modificar as políticas indigenistas e o próprio texto final da Constituição Federal de 1988. No lugar da integração e da assimilação, entrou em cena o reconhecimento do direito à autodeterminação. Outra conquista se refere à definição de terra indígena, cujo fundamento é a tradicionalidade dos modos de vida, afastando-se assim a ideia de ocupação imemorial e outras concepções equivocadas, como as de "aculturação" e "nomadismo".

Em paralelo às conquistas constitucionais, vale destacar a importância da Convenção 169 da Organização Internacional do Trabalho, de junho de 1989, ratificada pelo Brasil em julho de 2002. Desde então, a legislação e a política indigenista afirmam o reconhecimento da autonomia e do protagonismo indígena na gestão dos territórios e no ciclo de políticas públicas. Assim, foram criadas a Secretaria Especial de Saúde indígena, em 2010, e projetos educacionais específicos, que preveem a formulação de currículos estruturados nos territórios, saberes e línguas indígenas. Afinal, como destaca a antropóloga Manuela Carneiro da Cunha (2009, p. 257), "querer a integração não é, pois, querer assimilar-se: é querer ser ouvido, ter canais reconhecidos de participação no processo político do país, fazendo valer seus direitos específicos”.

Como sugere Renato Dagnino (2013, 2016; ver também Dagnino, Cavalcanti \& Costa, 2016; Sousa Lima, 2002), o processo de democratização do país depende da passagem do "Estado herdado" ao "Estado necessário". Para que as demandas de povos indígenas e de outros segmentos sociais historicamente marginalizados possam ser ouvidas e contempladas pelo Estado brasileiro, não basta o reconhecimento formal da cidadania. A "herança" de séculos de violência, exploração e deslocamentos forçados constituiu "um tipo particular de relação Estado-sociedade” (Dagnino, Cavalcanti, \& Costa, 2016, p. 34). Esta relação reflete a concentração de poder político e econômico responsável pelas desigualdades que caracterizam a sociedade brasileira.

Nesse sentido, "a transição de um modelo de Estado para o outro exige o aprimoramento das novas formas de gestão, como a gestão social, e uma efetiva atuação dos gestores públicos ao lado de outros atores, como ONGs e movimentos sociais" (Dagnino et al., 2016, p. 77). A criação do "Estado necessário”, compreendido como um Estado preparado para dialogar, acolher e atender as demandas dos diferentes segmentos sociais, depende, portanto, de um novo "estilo" ou "programa de formação" de gestores públicos. A compreensão da diversidade sociocultural, regional e linguística da sociedade brasileira deve estar presente na formação dos futuros profissionais da área, a fim de que sejam capazes de entender o caráter dos problemas que enfrentarão e como equacioná-los. Afinal,

... embora os gestores possuam relativamente pouco poder no processo decisório, eles participam como atores centrais do processo de operacionalização da agenda decisória, no momento de implementação da política. ... O paradoxo da situação que enfrenta o gestor é que essa "caixa de ferramentas" foi gerada no bojo de uma relação de forças políticas, de uma relação Estado-sociedade e de um arranjo institucional que reflete uma trajetória e uma situação pretérita ("Estado Herdado"). E que, é obvio, é distinta daquela que tende a ser alcançada ("Estado Necessário") com o aprofundamento do processo de democratização. (Dagnino et al., 2016, pp. 310, 312) 


\subsection{Questões para discussão}

\subsubsection{Quantos são os povos indígenas presentes no Brasil?}

Segundo os dados do Censo de 2010 (IBGE) e do Instituto Socioambiental (Ricardo \& Ricardo, 2017), estima-se que a população indígena no Brasil esteja entre 700 e 900 mil pessoas, distribuídas em 252 povos. As diferenças entre esses dados se devem ao modo de identificar os indivíduos e suas comunidades. No Censo, encontram-se primeiro os indivíduos para depois identificar os povos, enquanto o ISA se baseia em referências que partem geralmente dos povos para, em seguida, estimar o número de seus indivíduos. É possível que a diferença entre os totais populacionais se refira, principalmente, à população que se declarou indígena, mas não especificou uma etnia. Considerando apenas aqueles indivíduos que informaram sua etnia, os dados do IBGE e do ISA mostram-se mais próximos: 672.524 (IBGE, 2010) e 715.213 (Ricardo \& Ricardo, 2017). Em relação ao número de povos, a contagem do ISA considera as classificações acadêmicas, nas quais alguns povos são definidos como subgrupos de um mesmo povo: 252 povos (Ricardo \& Ricardo, 2017); 305 etnias (IBGE, 2010).

\subsubsection{Quando surgiram a legislação e as políticas a eles destinadas?}

Desde o Brasil Colônia, leis e alvarás reconheceram direitos aos povos nativos. Por exemplo, o Alvará Régio de 1680 definia que "os ditos Gentios, que assim decerem, e os mais, que há de presente, melhor se conservem nas Aldeias: hey por bem que senhores de suas fazendas, como o são no Sertão, sem lhe poderem ser tomadas, nem sobre ellas se lhe fazer moléstia”. A ideia de direito congênito e originário foi mantida em toda a legislação dos períodos colonial e republicano, inclusive na Lei de Terras de 1850. Segundo Souza (2013), da colonização ao regime militar, toda a legislação brasileira relativa aos povos indígenas promovia a ideia de integração, o que se pode identificar na redação dos textos constitucionais: "Se tente a sua civilização para que gozem dos bens permanentes de uma sociedade pacífica e doce" (1808); "Despertarlhes o desejo do trato social" (1845); "Até a sua incorporação à sociedade civilizada" (1928); "Incorporação à comunhão nacional” (1934, 1946, 1967, 1969); "Integrá-los, progressiva e harmoniosamente, à comunhão nacional" (1973). Porém, o primeiro serviço de Estado destinado exclusivamente aos povos indígenas surgiu apenas em 1910, com a criação do Serviço Nacional de Proteção aos Índios e Localização de Trabalhadores Nacionais (SPILTN), órgão ligado ao Ministério da Agricultura, Indústria e Comércio e que, anos mais tarde, teria o nome alterado para Serviço de Proteção aos Índios (SPI). Um dos fatos desencadeadores da nova política de Estado se referia ao conflito entre imigrantes europeus, assentados em Santa Catarina e no Rio Grande do Sul, e os povos Kaingang e Xokleng. No final da década de 1960, o SPI foi dissolvido em meio a uma infinidade de denúncias. O Promotor Jader de Figueiredo Correia realizou uma extensa investigação, que deu origem ao relatório que leva o seu nome (Relatório Figueiredo, com mais de 7.000 páginas). Em 1967, o SPI foi extinto e, no seu lugar, foi criada a Fundação Nacional do Índio (Funai), que é o órgão oficial indigenista do Estado brasileiro. Cabe à Funai proteger e promover os direitos dos povos indígenas no Brasil; identificar, delimitar, demarcar, regularizar e fiscalizar as terras tradicionalmente ocupadas; coordenar e implementar as políticas de proteção aos povos em condição de isolamento e aos recém-contatados; promover políticas voltadas ao desenvolvimento sustentável; estabelecer a articulação interinstitucional voltada ao reconhecimento de direitos sociais e de cidadania, com base nos princípios da autonomia e da autodeterminação dos povos indígenas.

\subsubsection{No que consistia o "poder tutelar"?}

Segundo o antropólogo Antonio Carlos de Souza Lima (2015), especialista no tema, trata-se de "uma modalidade de exercício de poder de um Estado concebido como nacional ..., configurando-se sob a forma de um regime de dominação juridicamente definido" (p. 430), baseado no "monopólio dos atos de definir e controlar o que são as coletividades sobre as quais incidirá" (p. 432). 


\subsubsection{Qual a importância da superação da tutela na Constituição Federal de 1988?}

No final da década de 1980, a população indígena no Brasil era de aproximadamente 200 mil pessoas, com cerca de 170 povos identificados. Ainda vigorava o entendimento de que a condição indígena seria "transitória", o que justificava a posição conservadora de não reconhecer direitos específicos e permanentes, mas somente condições provisórias e que permitissem a integração e a assimilação dos indígenas na sociedade brasileira. A administração pública era orientada pelo Estatuto do Índio, o que levava a política indigenista oficial a dividir as suas atribuições com diversas missões religiosas. Os avanços e as conquistas em relação à Constituição Federal de 1988 devem-se, principalmente, à ampliação da atuação indígena junto ao Congresso, por meio de lideranças, associações e movimentos organizados, nos âmbitos regional e nacional, a partir da década de 1970. Organizações de apoio (civis e eclesiais) promoveram campanhas junto à opinião pública, dentro e fora do Brasil, denunciando nas organizações multilaterais as consequências das políticas desenvolvimentistas do regime militar. Em 1978, uma proposta governamental de emancipação indígena teve efeito contrário ao esperado pelo regime, uma vez que serviu de estímulo para que as organizações indígenas criassem, em 1979, a União das Nações Indígenas (UNI). A UNI teve participação decisiva na Assembleia Nacional Constituinte, apresentando uma proposta de "programa mínimo", apoiado por centrais sindicais, associações profissionais (como a Associação Brasileira de Antropologia e a Sociedade Brasileira para o Progresso da Ciência), igrejas e partidos. O programa mínimo, apresentado à Subcomissão de Negros, Populações Indígenas, Pessoas Deficientes e Minorias no Congresso Nacional, baseava-se em cinco temaschave: 1. Reconhecimento dos direitos territoriais; 2. Demarcação e garantia das terras indígenas; 3 . Usufruto exclusivo; 4. Reassentamento dos posseiros; 5 . Reconhecimento e respeito às organizaçóes sociais e culturais dos povos indígenas com seus projetos de futuro, além das garantias de plena cidadania. Ao mesmo tempo, lideranças indígenas lançaram candidaturas à Constituinte: Davi Kopenawa Yanomami, pelo Partido dos Trabalhadores de Roraima (PT/RR); Gilberto Macuxi (PT/RR); Álvaro Tukano, pelo PT do Amazonas (AM); Biraci Yawanawá, pelo PT do Acre (AC); Nicolau Xavante, pelo Partido Democrático Trabalhista do Mato Grosso (PDT/MT); Idjahuri Karajá, pelo então Partido do Movimento Democrático Brasileiro de Goiás (PMDB/GO); Marcos Terena, pelo PDT do Distrito Federal (DF); Mário Juruna, pelo PDT do Rio de Janeiro (RJ); Karaí Mirin Guarani, pelo PT de São Paulo (SP). A Comissão Afonso Arinos (11/06/86 e 01/07/86) reconheceu o "programa mínimo" e o Ministério Público Federal foi instituído como parte legítima na defesa dos povos indígenas, cujas causas e processos passariam a tramitar exclusivamente na Justiça Federal. O Capítulo VIII - Dos Índios extinguiu a figura do poder tutelar ao reconhecer o direito à organização social e política de todos os povos indígenas presentes no país, assim como o respeito aos seus usos, costumes e tradições, tanto no interior de seus territórios quanto no âmbito da formulação, implementação e avaliação de políticas públicas.

\subsubsection{Quais as consequências do Capítulo VIII - Dos Índios para as ações do Estado?}

Institui os princípios da autonomia e da autodeterminação como fundamentos da ação estatal, que deve assegurar e promover as condições necessárias à reprodução física e cultural dos povos indígenas, assim como os direitos de cidadania plena e diferenciada.

\subsubsection{Ainda em relação ao Capítulo VIII, qual a importância da intersetorialidade na formulação e execução de políticas públicas para povos indígenas no Brasil?}

Toda ação estatal incidente em territórios indígenas repercute em diferentes domínios da vida dessas comunidades. Observe-se, por exemplo, o caso das políticas de gestão territorial, que estão intimamente 
relacionadas às diferentes concepções de bem viver, de ocupação e uso do território, de processos de ensino e aprendizagem referidos à apropriação do espaço, bem como ao conhecimento e às possibilidades de manejo. Principalmente no caso de políticas que possam alterar a rotina dessas comunidades ou quaisquer outros valores centrais aos modos de vida tradicionais, deve-se iniciar o seu processo de formulação com a realização de audiências públicas com lideranças e representantes indígenas. O consentimento prévio, livre e informado é um procedimento garantido pela legislação vigente e respaldado pelas convenções internacionais, das quais o Brasil é signatário.

\subsubsection{Como os direitos constitucionais dialogam com a Convenção 169 da Organização Internacional do Trabalho?}

A Convenção n, 169 da Organização Internacional do Trabalho (OIT) sobre Povos Indígenas e Tribais em Estados Independentes é o instrumento internacional mais atual e abrangente em relação às condições de vida e trabalho dos indígenas. Por ser um tratado internacional ratificado pelo Estado brasileiro, adquire caráter vinculante com a legislação vigente no país. A Convenção 169 e o texto constitucional compartilham dos mesmos sentidos em suas respectivas definições de terras indígenas, consideradas não apenas em função das áreas de ocupação destinadas à habitação, mas sobretudo em uma perspectiva integral do ambiente necessário ao usufruto coletivo e à reprodução física e cultural dos modos de vida. A Convenção 169 também estabelece o direito de consulta e de participação em relação ao uso, gestão e conservação dos territórios, prevendo inclusive o direito à indenização em caso de ameaças externas e de remoções resultantes das ações do Estado ou de empreendimentos realizados com a anuência do mesmo, cujos impactos incidam sobre essas populações e seus territórios.

\subsubsection{Em que consiste o direito à autodeterminação e quais as suas consequências para as políticas públicas?}

Para Eduardo Viveiros de Castro (1981, p. 235), a "autodeterminação, como ideia, sublinha ao contrário o caráter de Sujeito dos povos indígenas, sublinha sua diferença ativa [grifo do autor]". Nesse sentido, trata-se do desafio de conceber uma modalidade de políticas públicas em que eles sejam protagonistas e não apenas o público-alvo. O desafio é passar das políticas indigenistas para as políticas indígenas no âmbito das ações do Estado, o que exige um investimento em mecanismos de participação e de controle social, e a constituição de conselhos consultivos e deliberativos nos diferentes órgãos dos entes federativos.

\subsubsection{O que se poderia fazer para aprimorar essas políticas e para reduzir os possíveis efeitos adversos de sua implementação?}

Dois elementos são cruciais, a garantia da autodeterminação e a promoção da intersetorialidade das políticas públicas. Em um artigo de 1981, Eduardo Viveiros de Castro destacava que a ideia de autodeterminação pressupóe o caráter de "sujeito" dos povos indígenas, a "sua capacidade virtual de definir os rumos da própria história" (Viveiros de Castro, 1981, p. 235). O que caracteriza essa "diferença ativa" é a "interioridade irredutível" desses sujeitos. Nas palavras de Manuela Carneiro da Cunha (1979), a etnicidade seria, assim, uma forma de denominar a diferença revelada por uma cultura em face de outras, pois, mesmo que de modo "residual", trata-se de um domínio irredutível. O problema é que a ideia de autodeterminação tem um sentido claramente político, enquanto as políticas indigenistas brasileiras acenam, historicamente, para a integração e a "independência econômica" dos povos indígenas. Viveiros de Castro sugere que a "forma- 
Estado é essencialmente antagônica a qualquer autodeterminação autêntica" (1981, p. 236). Afinal, se os povos indígenas pudessem, de fato (e não apenas de direito), conduzir as políticas que lhe são destinadas, como ficariam os projetos de desenvolvimento nacional que dependem da exploração de recursos e territórios que esses mesmos povos não pretendem e não aceitam utilizar? Daí a diferença fundamental entre políticas indígenas (politics) e políticas indigenistas (policy). Autodeterminação e bem viver são conceitos que se pressupõem reciprocamente. Isto é, um não faz sentido e não se realiza sem o outro. Não por acaso, os povos indígenas têm-se dedicado a ocupar todos os espaços de representação política a que têm direito, a fim de que suas conceituações de "bem viver" não apenas sejam ouvidas, mas possam determinar as políticas que lhes dizem respeito.

Entretanto, a incorporação do conceito nas políticas indigenistas de países da América do Sul tem se mostrado pouco efetiva e, "frequentemente, as lideranças que trabalham com vistas a lutar pelas agendas políticas do viver bem de seus povos, não vivem bem; no sentido de que elas e eles não estão engajados em relações de criação de corpos, artefatos, subjetividades e territórios" (Belaunde, 2017, p. 196). Em suma, se não existem indígenas genéricos, tampouco existe um "bem viver indígena genérico". O problema da definição jurídico-política do conceito de terra indígena demonstra que a única forma possível de traduzir os conceitos e modos de vida desses povos, sem trair os seus sentidos originais, é transferir aos mesmos o protagonismo na definição, execução e avaliação de políticas públicas. Desde a promulgação da Constituição Federal de 1988, foram alcançadas importantes conquistas na criação de conselhos de participação e de controle social, nos quais lideranças indígenas puderam conceber e aprimorar políticas de saúde, educação, gestão territorial e ambiental. O papel dos profissionais não indígenas, nas diferentes áreas de atuação em administração pública, consiste em compreender essa especificidade e em promover políticas públicas em diálogo com representantes e lideranças indígenas.

\subsection{SugESTÃo DE DINÂMICA DE GRUPO}

Dividir a turma em grupos de até 5 pessoas. Durante 60 minutos, os grupos deverão ler o caso de ensino e, na sequência, identificar diferentes aspectos das políticas públicas para povos indígenas, com o apoio de matérias jornalísticas, conforme os exemplos abaixo. Após esse período, cada grupo terá até 10 minutos para compartilhar com a turma as impressões de seus integrantes. Finalmente, indica-se a realização de um debate, de 50 minutos, em formato de plenária, no qual as políticas públicas, os seus desafios e soluções poderão emergir. O tempo total da aula será de duas horas. 
Tabela 3 - Reportagens para consulta

\begin{tabular}{|c|c|}
\hline Matérias jornalísticas & Links de acesso \\
\hline $\begin{array}{l}\text { Benfatti, B. (2014). Índios } \\
\text { brasileiros estão cada vez } \\
\text { mais doentes. EntreTeses, } \\
\text { Unifesp, junho, 42-45. }\end{array}$ & $\begin{array}{l}\text { https://www.unifesp.br/reitoria/dci/apresentacao/item/2247-indios- } \\
\text { brasileiros-estao-cada-vez-mais-doentes }\end{array}$ \\
\hline $\begin{array}{l}\text { Damascena, B. ( } 2019 \text {, } \\
\text { setembro 5). A luta das } \\
\text { mulheres indigenas: } \\
\text { "vivemos um dos momentos } \\
\text { mais dramáticos". Universa. }\end{array}$ & $\begin{array}{l}\text { https://www.uol.com.br/universa/noticias/redacao/2019/09/05/a-luta-de- } \\
\text { mulheres-indigenas-vivemos-um-dos-momentos-mais-dramaticos.htm }\end{array}$ \\
\hline $\begin{array}{l}\text { Maisonnave, F. ( } 2016 \text {, } \\
\text { setembro 4). Bolsa Família } \\
\text { altera rotina de indígenas na } \\
\text { região do Xingu. Folha de } \\
\text { São Paulo. }\end{array}$ & http://folha.com/nol810078 \\
\hline $\begin{array}{l}\text { Pedroso, R. (2019, julho 2). } \\
\text { Para as indigenas da } \\
\text { Amazônia, parir é um ato } \\
\text { comunitário. Agência } \\
\text { Pública. }\end{array}$ & $\begin{array}{l}\text { https://apublica.org/2019/07/para-as-parteiras-indigenas-da-amazonia-o- } \\
\text { parto-natural-e-um-ato-comunitario/ }\end{array}$ \\
\hline
\end{tabular}

\section{REFERÊNCIAS}

Azevedo, M., Simoni, A.T., Cruz, A.K.R. (2017). O que o Censo de 2020 pode revelar sobre os povos indígenas no Brasil? In B. Ricardo \& F. Ricardo (Eds.). Povos indígenas no Brasil: 2011-2016 (pp.53-57). São Paulo: Instituto Socioambiental.

Baruzzi, R. G. (2007). A universidade na atenção à saúde dos povos indígenas: a experiência do Projeto Xingu da Universidade Federal de São Paulo/Escola Paulista de Medicina. Saúde e Sociedade, 16(2), 182-186.

Belaunde, L. E. (2017). Viver bem e a cerâmica: técnicas artefatuais e sociais na Amazônia. R@U: Revista de Antropologia da UFSCar, 9 (2), jul./dez., 185-200.

Benfatti, B. (2014). Índios brasileiros estão cada vez mais doentes. EntreTeses, Unifesp, 42-45.

Bicalho, P. (2019). Resistir era preciso: O Decreto de Emancipação de 1978, os povos indígenas e a sociedade civil no Brasil. Topoi, 20(40), 136-156.

Carneiro da Cunha, M. (2009). Cultura com aspas e outros ensaios. São Paulo: Cosac Naify.

Carneiro da Cunha, M. (2018). Índios Na Constituição. Novos estudos CEBRAP, 37(3), 429-443.

Coimbra Jr., C., Pontes, A., Santos, R. (2017). Cenários e tendências da saúde dos povos indígenas no Brasil. In B. Ricardo \& F. Ricardo (Eds.). Povos indígenas no Brasil: 2011-2016 (pp.118-122). São Paulo: Instituto Socioambiental.

Constituição da República Federativa do Brasil de 1988. Recuperado de http://www.planalto.gov.br/ccivil_03/Con stituicao/Constituicao.htm

Dagnino, R. (2013). A capacitação de gestores públicos: uma aproximação ao problema sob a ótica da administração política. Revista Brasileira de Administração Política, 6(1), 97-118.

Dagnino, R. (2016). Pensando remédios de médio prazo: o saber da burocracia e a mudança do estado. Revista Brasileira de Administração Política, 9(1), 179-183.

Dagnino, R., Cavalcanti, P.A., Costa, G. (2016). Gestão Estratégica Pública. São Paulo: Editora Fundação Perseu Abramo. 
Damascena, B. (2019, setembro 5). A luta das mulheres indígenas: "vivemos um dos momentos mais dramáticos". Universa. Recuperado de https://uol.com.br/universa/mulheres-indigenas

Decreto n$^{\circ}$ 5.051, de 19 de abril de 2004. Promulga a Convenção no 169 da Organização Internacional do Trabalho - OIT sobre Povos Indígenas e Tribais. Recuperado de http://www.planalto.gov.br/ccivil_03/_ato2004-2006/ 2004/decreto/d5051.htm

Gallois, D., Rosalen, J. (2017). Transformações nas relações: mudanças nos corpos e no padrão alimentar dos Wajãpi. In B. Ricardo \& F. Ricardo (Eds.). Povos indígenas no Brasil: 2011-2016 (p.22). São Paulo: Instituto Socioambiental.

Guedes, A. (2018). Especialistas apontam epidemia de cesarianas no Brasil. Agência Senado. Recuperado de https:// www12.senado.leg.br/epidemia-de-cesarianas/especialistas-apontam-epidemia-de-cesarianas

Guimara\#es, B., Bonilla, O., Pimentel, S. (2017). A diferença e o beneficio. In B. Ricardo \& F. Ricardo (Eds.). Povos indígenas no Brasil: 2011-2016 (pp.107-110). São Paulo: Instituto Socioambiental.

IBGE - Instituto Brasileiro de Geografia e Estatística. (2012). Censo Demográfico 2010: características gerais dos indígenas. Resultados do universo. Recuperado de https://biblioteca.ibge.gov.br/visualizacao/periodicos/95/cd _2010_indigenas_universo.pdf

ISA - Instituto Socioambiental. (2015). Localização e extensão das terras indígenas. Recuperado de https://pib.soci oambiental.org/pt/Localização_e_extensão_das_TIs

Lei n. 6.001, de 19 de dezembro de 1973. Dispõe sobre o Estatuto do Índio. Recuperado de http://www.planalto.go v.br/ccivil_03/Leis/L6001.htm

Maisonnave, F. (2016, setembro 4). Bolsa Família altera rotina de indígenas na região do Xingu. Folha de São Paulo. Recuperado de http://folha.com/no1810078.

Mendes, A.M., Leite, M.S., Langdon, E.J., Grisotti, M. (2018). O desafio da atenção primária na saúde indígena no Brasil. Rev Panam Salud Publica. 42, 1-6.

Ministério do Desenvolvimento Social e Agrário. (2016). Estudos Etnográficos sobre o Programa Bolsa Família entre Povos Indígenas. Brasília: MDS.

Monteiro, J. M. (2001). Tupis, Tapuias e historiadores: estudos de história indígena e do indigenismo. Tese de LivreDocência. Universidade Estadual de Campinas.

Oliveira, J.P. Filho (2016). O nascimento do Brasil e outros ensaios: "pacificação", regime tutelar e formação de alteridades. Rio de Janeiro: ContraCapa.

Pankararu, P. (2019). Fortalecimento dos povos e das organizações indígenas. São Paulo: FGV.

Pedroso, R. (2019, julho 2). Para as indígenas da Amazônia, parir é um ato comunitário. Agência Pública. Recuperado de https://apublica.org/2019/07/para-as-parteiras-indigenas-da-amazonia-o-parto-natural-e-um-ato-comunit ario/

Pompa, C. (2014). Os índios, entre antropologia e história: a obra de John Manuel Monteiro. Revista Brasileira de Informação Bibliográfica em Ciências Sociais (BIB), 74, 61-79.

Pontes, A. L., Alarcon, D. F., Kaingang, J. D., Santos, R. V. (2020). Vulnerabilidades, impactos e o enfrentamento ao COVID-19 no contexto dos povos indígenas: reflexões para a ação. Observatório COVID-19 Fiocruz. Recuperado de https://fiocruz.br/41196

Ricardo, B., Ricardo, F. (2017). Povos indígenas no Brasil: 2011-2016. São Paulo: Instituto Socioambiental.

Soares, L.P. (2015). Perfil nutricional e alterações metabólicas na população adulta Xavante das reservas indígenas de São Marcos e Sangradouro MT. Tese de Doutorado, Faculdade de Medicina de Ribeirão Preto, Universidade de São Paulo.

Souza Filho, C.F.M de. (2013). Dos índios. In J. Canotilho, G. Mendes, I. Sarlec, \& L. Strack, (Orgs.). Comentários à Constituição Brasileira (pp. 2147-2157). São Paulo: Saraiva/Almedina, v. 1.

Souza Lima, A.C. (2002). Problemas de qualificação de pessoal para novas formas de ação indigenista. In A.C. Souza Lima \& M. Barroso-Hoffmann (Orgs.). Estado e Povos Indígenas: bases para uma nova política indigenista II (pp.83-95). Rio de Janeiro: Contra Capa/LACED. 
Souza Lima, A.C., Macedo e Castro, J.P. (2015). Notas para uma abordagem antropológica da(s) política(s) pública(s). Revista Anthropológicas, Recife, 26(2), 17-54.

Souza Lima, A.C. (2015). Sobre tutela e participação: povos indígenas e formas de governo no brasil, séculos XX/XXI. Mana, 21(2), 425-457.

Viveiros de Castro, E. (1981). Autodeterminação indígena como valor. Anuário Antropológico, 83, 20-37.

Welch, J.R. (2014). Fórum: saúde e povos indígenas no Brasil. Introdução. Cadernos de Saúde Pública, 30(4), 851-854.

\section{Notas}

[i]Benfatti, B. (2014). Índios brasileiros estão cada vez mais doentes. EntreTeses, Unifesp, junho. Recuperado de https://www.un ifesp.br/reitoria/dci/publicacoes/entreteses/item/2247-indios-brasileiros-estao-cada-vez-mais-doentes

[ii]Douglas Rodrigues (como citado em Maisonnave, 2016, setembro 4). Bolsa Família altera rotina de indígenas na região do Xingu. Folba de São Paulo. Recuperado de http://folha.com/no1810078

[iii]Artur Mendes (como citado em Maisonnave, 2016, setembro 4). Bolsa Família altera rotina de indígenas na região do Xingu. Folha de São Paulo. Recuperado de http://folha.com/no1810078

[iv]Maisonnave, F. (2016, setembro 4). Bolsa Família altera rotina de indígenas na região do Xingu. Folha de São Paulo. Recuperado de http://folha.com/no1810078

[v]BRASIL, Ministério do Desenvolvimento Social e Agrário (2016, p. 125).

[vi]Gallois e Rosalen (2017, p. 22).

[vii]Marcelo Kamayurá (como citado em Maisonnave, 2016, setembro 4). Bolsa Família altera rotina de indígenas na região do Xingu. Folha de São Paulo. Recuperado de http://folha.com/no1810078 [viii] Watatakalu Yawalapiti (como citado em Damascena, 2019, setembro 5). A luta de mulheres indígenas: "vivemos um dos momentos mais dramáticos". Portal Universa. Recuperado de https://www.uol.com.br/universa/noticias/redacao/2019/09/05/a-luta-de-mulheres-indigenas-vivemos-um-dos -momentos-mais-dramaticos.htm

[ix]Paulo Supretaprã (como citado em Welch, 2014, p. 852).

[x] Guedes (2018).

[xi]Lourdes Firmino (como citado em Pedroso, 2019, julho 2). Para as indígenas da Amazônia, parir é um ato comunitário. Agência Pública. Recuperado de https://apublica.org/2019/07/para-as-parteiras-indigenas-da-amazonia-o-parto-natural-e-um-ato-comu nitario/

[xii]Pontes, A. L., Alarcon, D. F., Kaingang, J. D., Santos, R. V. (2020). Vulnerabilidades, impactos e o enfrentamento ao COVID-19 no contexto dos povos indígenas: reflexões para a ação. Observatório COVID-19 Fiocruz, 5p., 2020. [xiii] Para mais informações sobre os povos indígenas no Brasil e os seus respectivos territórios, recomendam-se as seguintes páginas: https://pib. socioambiental.org/ e https://terrasindigenas.org.br/, ambas de autoria do Instituto Socioambiental. 